\title{
Mortality risk by peak serum creatinine in hospital episodes complicated by acute kidney injury
}

\author{
Authors: Benjamin James, ${ }^{A}$ Lynne Sykes, ${ }^{A}$ Emma Flanagan, ${ }^{A}$ Smeeta Sinha, ${ }^{B}$ Philip Kalra ${ }^{B}$ and Darren Green ${ }^{B}$
}

\begin{tabular}{|c|c|c|c|c|c|c|}
\hline & AKI stage 1 & AKI stage 2 & AKI stage 3 & AKI no CKD & AKI on CKD & CKD no AKI \\
\hline $\mathrm{pSCr}(\mu \mathrm{mol} / \mathrm{L})$ & $\mathrm{n} /$ deaths (\%) & n / deaths (\%) & $\mathrm{n} /$ deaths (\%) & n / deaths (\%) & n / deaths (\%) & $\mathrm{n} /$ deaths (\%) \\
\hline$\leq 100$ & $\begin{array}{l}3,861 / 342 \\
(8.9 \%)\end{array}$ & $\begin{array}{l}458 / 80 \\
(17.5 \%)\end{array}$ & $\begin{array}{l}68 / 17 \\
(25.0 \%)\end{array}$ & $\begin{array}{l}4,335 / 433 \\
(10.0 \%)\end{array}$ & $\begin{array}{l}52 / 6 \\
(11.5 \%)\end{array}$ & $\begin{array}{l}1,594 / 41 \\
(2.6 \%)\end{array}$ \\
\hline $101-200$ & $\begin{array}{l}4,331 / 633 \\
(14.6 \%)\end{array}$ & $\begin{array}{l}1,475 / 367 \\
(24.9 \%)\end{array}$ & $\begin{array}{l}434 / 125 \\
(28.8 \%)\end{array}$ & $\begin{array}{l}5,684 / 1,018 \\
(17.9 \%)\end{array}$ & $\begin{array}{l}556 / 107 \\
(19.2 \%)\end{array}$ & $\begin{array}{l}3,944 / 141 \\
(3.6 \%)\end{array}$ \\
\hline $201-300$ & $\begin{array}{l}842 / 186 \\
(22.1 \%)\end{array}$ & $\begin{array}{l}547 / 176 \\
(32.2 \%)\end{array}$ & $\begin{array}{l}301 / 102 \\
(33.9 \%)\end{array}$ & $\begin{array}{l}1,288 / 370 \\
(28.7 \%)\end{array}$ & $\begin{array}{l}402 / 94 \\
(23.4 \%)\end{array}$ & $\begin{array}{l}782 / 37 \\
(4.7 \%)\end{array}$ \\
\hline $301-400$ & $\begin{array}{l}185 / 42 \\
(22.7 \%)\end{array}$ & $\begin{array}{l}132 / 42 \\
(31.8 \%)\end{array}$ & $\begin{array}{l}337 / 110 \\
(32.6 \%)\end{array}$ & $\begin{array}{l}443 / 145 \\
(32.7 \%)\end{array}$ & $\begin{array}{l}211 / 49 \\
(23.2 \%)\end{array}$ & $\begin{array}{l}200 / 12 \\
(6.0 \%)\end{array}$ \\
\hline$>400$ & $\begin{array}{l}120 / 15 \\
(12.5 \%)\end{array}$ & $\begin{array}{l}2 / 0 \\
(0.0 \%)\end{array}$ & $\begin{array}{l}742 / 194 \\
(26.1 \%)\end{array}$ & $\begin{array}{l}530 / 150 \\
(28.3 \%)\end{array}$ & $\begin{array}{l}334 / 59 \\
(17.7 \%)\end{array}$ & $\begin{array}{l}254 / 13 \\
(5.1 \%)\end{array}$ \\
\hline
\end{tabular}

\section{Introduction}

Acute kidney injury (AKI) is common in hospitalised patients and provides valuable prognostic information, although there is suggestion of negligible mortality difference between AKI stages 2 and $3{ }^{1,2}$ AKI stage is principally determined by proportional serum creatinine ( $\mathrm{SCr}$ ) changes, not by absolute values. We hypothesised that establishing prognostic differences within and between AKI stages can be improved by using peak $\mathrm{SCr}(\mathrm{pSCr})$ values as well as proportional change. To address a secondary aim, we compared prognosis based on pSCr between patients with AKI and those with chronic kidney disease (CKD). This was to determine whether the outcome for any given $\mathrm{SCr}$ is worse in $\mathrm{AKI}$ or $\mathrm{CKD}$.

\section{Methods}

Anonymised data for all adult inpatient episodes at Salford Royal Hospital from March 2014 to August 2018 were acquired as previously described. ${ }^{3}$ Exclusion criteria were: pregnancy, renal transplant, maintenance dialysis, transfers for tertiary nephrology care, insufficient SCr data. AKI events were

Authors: A Salford Royal NHS Foundation Trust, Salford, UK;

${ }^{B}$ Salford Royal NHS Foundation Trust, Salford, UK and University of Manchester, Manchester, UK determined using the NHS England algorithm. ${ }^{4} \mathrm{pSCr}$ for each hospital episode was classified as $\leq 100,101-200,201-300$, 301-400 or $>400 \mu \mathrm{mol} / \mathrm{L}$. Odds ratio (OR) for in-hospital death was determined for each pSCr category against a reference group of no AKI and $\mathrm{pSCr} \leq 100 \mu \mathrm{mol} / \mathrm{L}$, using binary logistic regression adjusted for age, gender and ICD-10 coded comorbidities. Results were compared between AKI stages and CKD status.

\section{Results}

There were 163,428 inpatient episodes, of which 21,545 were excluded. Of 141,883 included episodes ( $52.6 \%$ female; mean age 56.5 \pm 22.1 years; CKD 5.9\%; inpatient death 3.8\%), 9.8\% were complicated by AKI. Highest AKI stage was one in 9,339 (6.6\%), two in 2,614 (1.8\%) and three in 1,882 (1.3\%). Table 1 displays the number of admissions, AKI and deaths in each pSCr classification, categorised by AKI stage and CKD status. Fig 1 displays the OR for mortality between pSCr categories. Mortality risk generally rose with increasing pSCr, and there was a greater risk with advancing AKI stage. The highest mortality risk was in AKI stage 3, pSCr 201-300 $\mu \mathrm{mol} / \mathrm{L}$ (OR 15.22 (confidence interval 11.71-19.77); $\mathrm{p}<0.001$ ). Of note, mortality risk was lower for $\mathrm{pSCr}>400 \mu \mathrm{mol} / \mathrm{L}$ in patients with AKI stages 1 (OR $3.70(2.11-6.51) ; \mathrm{p}<0.001)$ and 3 (OR 8.65 (7.19-10.41); $\mathrm{p}<0.001)$ compared with categories 201-300 and 301-400 $\mu \mathrm{mol} / \mathrm{L}$. In AKI stage 3, pSCr $>400 \mu \mathrm{mol} / \mathrm{L}$ had 
a) Mortality Risk by AKI Stage

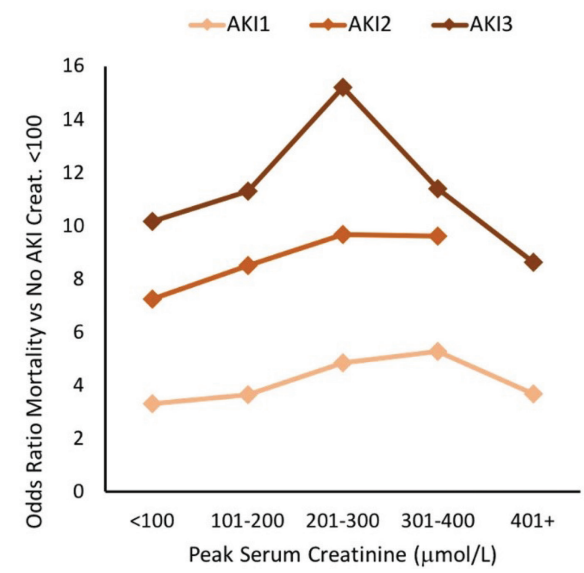

b) Mortality Risk by AKI/CKD status

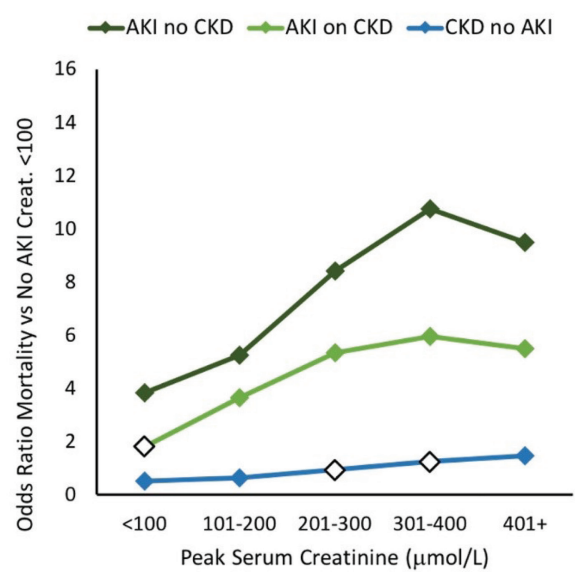

Fig 1. Mortality risk by peak serum creatinine. A blank marker denotes that this odds ratio is not significant $(p>0.05)$ : all other results are significant $(p>0.05)$. the lowest $\mathrm{OR}$ across the range of pSCr, including pSCr $\leq 100$ $\mu \mathrm{mol} / \mathrm{L}$ (OR 10.18 (5.65-18.36); $\mathrm{p}<0.001)$. Sub-analyses showed that overall adjusted mortality risk was significantly higher in AKI stage 3 vs 2 (OR 1.25 (1.09-1.44); $\mathrm{p}=0.001$ ), although when assessed across pSCr categories this was not significant at extremes. In patients with CKD, AKI was associated with significantly higher mortality across pSCr levels.

\section{Conclusion}

Mortality risk is high in hospital episodes complicated by AKI and risk increases proportionately with AKI stage and pSCr, except in patients with $\mathrm{pSCr}>400 \mu \mathrm{mol} / \mathrm{L}$. For a given $\mathrm{pSCr}$, AKI carries significantly greater mortality risk than CKD. The absolute value of $\mathrm{SCr}$ has relevance for prognosis during inpatient AKI episodes, beyond that indicated by AKI stage alone.

\section{Conflicts of interest}

None declared.

\section{References}

1 Kellum JA, Lameire N, Aspelin P et al. Kidney Disease: Improving Global Outcomes (KDIGO) Acute Kidney Injury Work Group. KDIGO clinical practice guideline for acute kidney injury. Kidney Int Suppl 2012;2:1-138.

2 Selby NM, Crowley L, Fluck RJ et al. Use of electronic results reporting to diagnose and monitor AKI in hospitalized patients. Clin J Am Soc Nephrol 2012;7:533-40.

3 Sykes L, Kalra PA, Green D. Comparison of impact on death and critical care admission of acute kidney injury between common medical and surgical diagnoses. PLoS One 2019;14:e0215105.

4 NHS England. Acute kidney injury (AKI) algorithm. NHS. www.england.nhs.uk/akiprogramme/aki-algorithm [Accessed 20 October 2019]. 